\title{
Application of Intuitionistic Fuzzy Multisets in Appointment Process
}

\author{
P. A. Ejegwa \\ Dept. of \\ Maths/Statistics/Computer \\ Science, University of \\ Agriculture, P.M.B. 2373, \\ Makurdi-Nigeria
}

\author{
L. N. Kwarkar \\ Dept. of \\ Maths/Statistics/Computer \\ Science, University of \\ Agriculture, P.M.B. 2373, \\ Makurdi-Nigeria
}

\author{
K. N. Ihuoma \\ Dept. of \\ Maths/Statistics/Computer \\ Science, University of \\ Agriculture, P.M.B. 2373, \\ Makurdi-Nigeria
}

\begin{abstract}
In this paper, a precise note on intuitionistic fuzzy multisets is given and the concept is applied to appointment process. This process was carried out assuming three sets of 10-man committees screened five candidates vying for positions in an organization independently to obtain intuitionistic fuzzy multi-data. The obtained data are compared with the organization requirements of appointments via a new distance measure.
\end{abstract}

\section{Keywords}

Fuzzy multisets, intuitionistic fuzzy sets, intuitionistic fuzzy multisets, intuitionistic fuzzy sets, appointment process, distance measures.

\section{INTRODUCTION}

The invention of fuzzy sets by Zadeh [22] as the generalization of crisp sets proffers solution to uncertainties in decision making, artificial intelligent, engineering and computer programming. Zadeh is single-handedly responsible for the early development of fuzzy set which he defined as the collection of object with graded membership. The concept of characteristic function in crisp set was replaced by membership function which take elements from a universe $\mathrm{X}$ to form image in a closed interval [0, 1]. Yager [21] generalized the concept of fuzzy sets to form a set called fuzzy multiset. By extending fuzzy set in such a way that it contains two functions called the membership function and non-membership function with hesitation zone, Atanassov [1] proposed the idea of intuitionistic fuzzy set which is more viable in tackling uncertainties as seen in [2], [7]. Shinoj and Sunil [18] introduced intuitionistic fuzzy multisets from the combination of the concepts of fuzzy multisets and intuitionistic fuzzy sets. However, intuitionistic fuzzy multiset is more or less the generalization of intuitionistic fuzzy set or the extension of fuzzy multiset [13]. Some researchers have studied the concept of intuitionistic fuzzy multisets and its applications in medical diagnosis, binomial distribution, pattern recognition, robotics science, etc. as seen in [3], [4], [5], [6], [8], [9], [10], [11], [14], [15], [16], [17], [19], [20].

Owning to the fact that, the idea of intuitionistic fuzzy multisets is more accurate in handling imprecision and uncertainties, we seek to apply its concept to appointment procedure or process as an improvement of the work in [7] using a new distance measure in [12].

\section{INTUITIONISTIC FUZZY MULTISETS}

Definition 2.1[1]. Let $X$ be nonempty set. An intuitionistic fuzzy set (IFS) $A$ in $X$ is an object having the form $A=$ $\left\{\left\langle x, \mu_{A}(x), v_{A}(x)\right\rangle: x \in X\right\}$, where the functions
$\mu_{\mathrm{A}}(\mathrm{x}), v_{\mathrm{A}}(\mathrm{x}): \mathrm{X} \rightarrow[0,1]$ define the degree of membership and degree of non-membership of the element $x \in X$ to the set A. For every $\mathrm{x} \in \mathrm{X}, 0 \leq \mu_{\mathrm{A}}(\mathrm{x})+v_{\mathrm{A}}(\mathrm{x}) \leq 1$.

Furthermore, $\pi_{A}(x)=1-\mu_{A}(x)-v_{A}(x)$ is the intuitionistic fuzzy set index or hesitation margin and is the degree of indeterminacy concerning the membership of $x$ in $A$, then $\pi_{A}(x) \in[0,1]$. Whenever $\pi_{A}(x)=0$, an IFS reduces automatically to fuzzy set.

Definition 2.2 [5]. Let X be nonempty set. An IFMS A drawn from $X$ is given as $\mathrm{A}=\left\{\left\langle\mathrm{Q}_{\mathrm{A}}^{1}(\mathrm{x}), \ldots, \mathrm{Q}_{\mathrm{A}}^{\mathrm{n}}(\mathrm{x}), \ldots, v_{\mathrm{A}}^{1}(\mathrm{x}), \ldots, v_{\mathrm{A}}^{\mathrm{n}}(\mathrm{x}), \ldots\right\rangle: \mathrm{x} \in \mathrm{X}\right\}$ where the functions $\mu_{A}^{\mathrm{i}}(\mathrm{x}), v_{\mathrm{A}}^{\mathrm{i}}(\mathrm{x}): \mathrm{X} \rightarrow[0,1]$ define the belongingness degrees and the non-belongingness degrees of $A$ in $X$ such that $0 \leq \mu_{A}^{i}(x)+v_{A}^{i}(x) \leq 1$ for $i=1, \ldots$. If the sequence of the membership functions and non-membership

(belongingness functions and non-belongingness functions have only $n$-terms (i.e. finite), $n$ is called the dimension of $A$. Consequently $\mathrm{A}=\left\{\left\langle\mathrm{Q}_{\mathrm{A}}^{1}(\mathrm{x}), \ldots, \mathrm{Q}_{\mathrm{A}}^{\mathrm{n}}(\mathrm{x}), v_{\mathrm{A}}^{1}(\mathrm{x}), \ldots, v_{\mathrm{A}}^{\mathrm{n}}(\mathrm{x})\right\rangle: \mathrm{x} \in\right.$ $X\}$ for $i=1, \ldots, n$. when no ambiguity arises, we write $A=\left\{\left\langle\mathbb{Q}_{A}^{i}(x), v_{A}^{i}(x)\right\rangle: x \in X\right\}$.

For each IFMS $A$ in $X, \pi_{A}^{i}(x)=1-\mu_{A}^{i}(x)-v_{A}^{i}(x)$ is the intuitionistic fuzzy multisets index or hesitation margin of $\mathrm{x}$ in A. The hesitation margin $\pi_{A}^{i}(x)$ for each $i=1, \ldots, n$ is the degree of non-determinacy of $x \in X$, to the set $A$ and $\pi_{A}^{i}(x) \in$ $[0,1]$. Similarly, $\pi_{A}^{i}(x)$ as in IFS, is the function that expresses lack of knowledge of whether $\mathrm{x} \in \mathrm{A}$ or $\mathrm{x} \notin \mathrm{A}$. Then, $\mu_{A}^{i}(x)+v_{A}^{i}(x)+\pi_{A}^{i}(x)=1$ for each $i=1, \ldots$. n.

We henceforth denote the set of all intuitionistic fuzzy multisets over $\mathrm{X}$ as IFMS(X). Also, we denote an intuitionistic fuzzy multiset $\mathrm{A}$ as $\mathrm{A}=\left(\mu_{\mathrm{A}}^{\mathrm{i}}(\mathrm{x}), v_{\mathrm{A}}^{\mathrm{i}}(\mathrm{x})\right)$ for simplicity.

Definition 2.3. Let $\left\{A_{j}\right\}_{j \in J}$ be an arbitrary family of IFMSs in $X$, where $A=\left(\mu_{A_{j}}^{i}(x), v_{A_{j}}^{i}(x)\right) \in \operatorname{IFMS}(X)$ for each $j \in J$, we define

$\bigcap_{\mathrm{j} \in \mathrm{J}} \mathrm{A}=\left(\Lambda \mu_{\mathrm{A}_{\mathrm{j}}}^{\mathrm{i}}(\mathrm{x}), \vee v_{\mathrm{A}_{\mathrm{j}}}^{\mathrm{i}}(\mathrm{x})\right)$ and

$\mathrm{U}_{\mathrm{j} \in \mathrm{J}} \mathrm{A}=\left(\mathrm{V} \mu_{\mathrm{A}_{\mathrm{j}}}^{\mathrm{i}}(\mathrm{x}), \wedge v_{\mathrm{A}_{\mathrm{j}}}^{\mathrm{i}}(\mathrm{x})\right) \forall \mathrm{x} \in \mathrm{X}$.

Definition 2.4[13]. Let $X$ be nonempty. If $A \in \operatorname{IFMS}(X)$, then;

(i) $A=\left\{\left\langle x, \mu_{A}^{\mathrm{i}}(\mathrm{x}), 1-\mu_{\mathrm{A}}^{\mathrm{i}}(\mathrm{x})\right\rangle: \mathrm{x} \in \mathrm{X}\right\}$

(ii) ) $\diamond \mathrm{A}=\left\{\left\langle\mathrm{x}, 1-v_{\mathrm{A}}^{\mathrm{i}}(\mathrm{x}), v_{\mathrm{A}}^{\mathrm{i}}(\mathrm{x})\right\rangle: \mathrm{x} \in \mathrm{X}\right\}$. 
Definition 2.5. For any two IFMSs A and B drawn from X, the following operations hold.

(i)Inclusion: $\mathrm{A} \subseteq \mathrm{B} \Rightarrow \mu_{\mathrm{A}}^{\mathrm{i}}(\mathrm{x}) \leq \mu_{\mathrm{B}}^{\mathrm{i}}(\mathrm{x}) \quad$ and $\quad v_{\mathrm{A}}^{\mathrm{i}}(\mathrm{x}) \geq$ $v_{\mathrm{B}}^{\mathrm{i}}(\mathrm{x}) \forall \mathrm{x} \in \mathrm{X}$.

(ii)Equality: $\mathrm{A}=\mathrm{B} \Rightarrow \mu_{\mathrm{A}}^{\mathrm{i}}(\mathrm{x})=\mu_{\mathrm{B}}^{\mathrm{i}}(\mathrm{x}) \quad$ and $\quad v_{\mathrm{A}}^{\mathrm{i}}(\mathrm{x})=$ $v_{\mathrm{B}}^{\mathrm{i}}(\mathrm{x}) \forall \mathrm{x} \in \mathrm{X}$.

(iii) Complement: $\mathrm{A}^{\mathrm{c}}=v_{\mathrm{A}}^{\mathrm{i}}(\mathrm{x}), \mu_{\mathrm{A}}^{\mathrm{i}}(\mathrm{x}) \forall \mathrm{x} \in \mathrm{X}$.

(iv)Union: $\mathrm{A} \cup \mathrm{B}=\mu_{\mathrm{A}}^{\mathrm{i}}(\mathrm{x}) \vee \mu_{\mathrm{B}}^{\mathrm{i}}(\mathrm{x}), \nu_{\mathrm{A}}^{\mathrm{i}}(\mathrm{x}) \wedge \nu_{\mathrm{B}}^{\mathrm{i}}(\mathrm{x}) \forall \mathrm{x} \in \mathrm{X}$.

(v)Intersection: $\mathrm{A} \cap \mathrm{B}=\mu_{\mathrm{A}}^{\mathrm{i}}(\mathrm{x}) \wedge \mu_{\mathrm{B}}^{\mathrm{i}}(\mathrm{x}), v_{\mathrm{A}}^{\mathrm{i}}(\mathrm{x}) \vee v_{\mathrm{B}}^{\mathrm{i}}(\mathrm{x}) \quad \forall \mathrm{x} \in \mathrm{X}$.

(vi)Addition: $\mathrm{A} \oplus \mathrm{B}=\mu_{\mathrm{A}}^{\mathrm{i}}(\mathrm{x})+\mu_{\mathrm{B}}^{\mathrm{i}}(\mathrm{x})-\mu_{\mathrm{A}}^{\mathrm{i}}(\mathrm{x}) \mu_{\mathrm{B}}^{\mathrm{i}}(\mathrm{x})$,

$v_{\mathrm{A}}^{\mathrm{i}}(\mathrm{x}) v_{\mathrm{B}}^{\mathrm{i}}(\mathrm{x}) \forall \mathrm{x} \in \mathrm{X}$.

(vii)Multiplication: $\mathrm{A} \otimes \mathrm{B}=\mu_{\mathrm{A}}^{\mathrm{i}}(\mathrm{x}) \mu_{\mathrm{B}}^{\mathrm{i}}(\mathrm{x}), \quad v_{\mathrm{A}}^{\mathrm{i}}(\mathrm{x})+v_{\mathrm{B}}^{\mathrm{i}}(\mathrm{x})-$ $v_{\mathrm{A}}^{\mathrm{i}}(\mathrm{x}) v_{\mathrm{B}}^{\mathrm{i}}(\mathrm{x}) \forall \mathrm{x} \in \mathrm{X}$.

(viii)Difference: $\mathrm{A}-\mathrm{B}=$ ? $_{\mathrm{A}}^{\mathrm{i}}(\mathrm{x}) \wedge v_{\mathrm{B}}^{\mathrm{i}}(\mathrm{x}), v_{\mathrm{A}}^{\mathrm{i}}(\mathrm{x}) \vee ?_{\mathrm{B}}^{\mathrm{i}}(\mathrm{x})$ $\forall \mathrm{x} \in \mathrm{X}$.

Definition 2.6. Let $A \in \operatorname{IFMS}(X)$, we define the support of A and the cross point of $A$ as follow.

(i) $\operatorname{Supp}(\mathrm{A})=\left\{\mathrm{x} \in \mathrm{X}: \mu_{\mathrm{A}}^{\mathrm{i}}(\mathrm{x})>0, v_{\mathrm{A}}^{\mathrm{i}}(\mathrm{x})<1\right\}, \forall \mathrm{x} \in \mathrm{X}$.

(ii) The crossover point of $\mathrm{A}$ is $\left\{\mathrm{x} \in \mathrm{X}: \mu_{\mathrm{A}}^{\mathrm{i}}(\mathrm{x})=\frac{1}{2}, v_{\mathrm{A}}^{\mathrm{i}}(\mathrm{x})=\right.$ $\left.\frac{1}{2}\right\} \forall \mathrm{x} \in \mathrm{X}$.

Definition 2.7. Let $A, B \in \operatorname{IFMS}(X)$, the new distance measure between $A$ and $B$ is given as
$\mathrm{d}(\mathrm{A}, \mathrm{B})=\frac{1}{2 \mathrm{n}} \sum_{\mathrm{i}=1}^{\mathrm{n}}\left[\left|\mu_{\mathrm{A}}^{\mathrm{i}}\left(\mathrm{x}_{\mathrm{i}}\right)-\mu_{\mathrm{B}}^{\mathrm{i}}\left(\mathrm{x}_{\mathrm{i}}\right)\right|+|| \mu_{\mathrm{A}}^{\mathrm{i}}\left(\mathrm{x}_{\mathrm{i}}\right)-\right.$

$v_{A}^{\mathrm{i}}\left(\mathrm{x}_{\mathrm{i}}\right)|-| \mu_{\mathrm{B}}^{\mathrm{i}}\left(\mathrm{x}_{\mathrm{i}}\right)-v_{\mathrm{B}}^{\mathrm{i}}\left(\mathrm{x}_{\mathrm{i}}\right)||+|| \mu_{\mathrm{A}}^{\mathrm{i}}\left(\mathrm{x}_{\mathrm{i}}\right)-\pi_{\mathrm{A}}^{\mathrm{i}}\left(\mathrm{x}_{\mathrm{i}}\right) \mid-$ $\left.\left|\mu_{\mathrm{B}}^{\mathrm{i}}\left(\mathrm{x}_{\mathrm{i}}\right)-\pi_{\mathrm{B}}^{\mathrm{i}}\left(\mathrm{x}_{\mathrm{i}}\right)\right| \mid\right] \forall x \in X$.

\section{INTUITIONISTIC FUZZY MULTISETS AND APPOINTMENT PROCESS}

Suppose a new organization wants to appoint members into its management board or an old organization intends to reshuffle it cabinet, the challenge is how to avoid fitting round peg in a flat hole when the to be managers seem to be relatively qualified. In [7], this situation was handled by using intuitionistic fuzzy sets approach. It is assumed that a 10member committee scored or screened the candidates using intuitionistic fuzzy values.

Since it will be difficult to ascertain how impartial the 10member committee is, in this method we assume the candidate are screened by three set of 10-member committees such that each of the committees are independent. By compiling the results from each of the three committees, intuitionistic fuzzy multi-data is obtained.

Let $C=\left\{c_{1}, c_{2}, c_{3}, c_{4}, c_{5}\right\}$ be the set of candidates to be appointed, let $\mathrm{Q}=$ \{honesty, team spirit, hardworking, transparency, academic fitness, experience, accountability, probity $\}$ be the set of qualifications expected from the candidates, and $P=\left\{p_{1}, p_{2}, p_{3}, p_{4}, p_{5}\right\}$ be the set of positions to be occupied. Assumed after the committees screened the candidates, the following results were obtained.

Table 1. Candidates and Qualifications

\begin{tabular}{|c|l|l|l|l|l|l|l|l|}
\hline & honesty & team spirit & hard working & transparency & $\begin{array}{l}\text { academic } \\
\text { fitness }\end{array}$ & experience & accountability & probity \\
\hline$c_{1}$ & $(0.50,0.40)$ & $(0.80,0.20)$ & $(0.40,0.30)$ & $(0.40,0.50)$ & $(0.60,0.20)$ & $(0.7,0.10)$ & $(0.75,0.10)$ & $(0.65,0.15)$ \\
& $(0.40,0.35)$ & $(0.90,0.15)$ & $(0.50,0.40)$ & $(0.50,0.40)$ & $(0.50,0.15)$ & $(0.6,0.05)$ & $(0.80,0.15)$ & $(0.70,0.25)$ \\
& $(0.60,0.45)$ & $(0.70,0.25)$ & $(0.30,0.20)$ & $(0.30,0.60)$ & $(0.70,0.25)$ & $(0.8,0.15)$ & $(0.85,0.05)$ & $(0.75,0.20)$ \\
\hline$c_{2}$ & $(0.80,0.20)$ & $(0.60,0.30)$ & $(0.60,0.10)$ & $(0.30,0.50)$ & $(0.80,0.10)$ & $(0.80,0.15)$ & $(0.90,0.00)$ & $(0.80,0.15)$ \\
& $(0.75,0.25)$ & $(0.50,0.35)$ & $(0.50,0.15)$ & $(0.50,0.40)$ & $(0.75,0.15)$ & $(0.75,0.10)$ & $(0.85,0.00)$ & $(0.85,0.05)$ \\
& $(0.85,0.15)$ & $(0.70,0.25)$ & $(0.70,0.05)$ & $(0.10,0.60)$ & $(0.85,0.05)$ & $(0.85,0.05)$ & $(0.95,0.00)$ & $(0.75,0.10)$ \\
\hline$c_{3}$ & $(0.60,0.30)$ & $(0.70,0.30)$ & $(0.70,0.20)$ & $(0.20,0.50)$ & $(0.85,0.15)$ & $(0.75,0.15)$ & $(0.95,0.15)$ & $(0.65,0.15)$ \\
& $(0.50,0.40)$ & $(0.60,0.40)$ & $(0.60,0.30)$ & $(0.10,0.60)$ & $(0.90,0.10)$ & $(0.85,0.20)$ & $(0.90,0.10)$ & $(0.70,0.25)$ \\
& $(0.70,0.20)$ & $(0.80,0.20)$ & $(0.80,0.10)$ & $(0.30,0.70)$ & $(0.95,0.05)$ & $(0.80,0.25)$ & $(0.85,0.05)$ & $(0.75,0.20)$ \\
\hline$c_{4}$ & $(0.70,0.10)$ & $(0.80,0.10)$ & $(0.90,0.00)$ & $(0.50,0.40)$ & $(0.55,0.35)$ & $(0.75,0.10)$ & $(0.85,0.00)$ & $(0.65,0.15)$ \\
& $(0.60,0.10)$ & $(0.75,0.05)$ & $(0.85,0.00)$ & $(0.60,0.35)$ & $(0.45,0.30)$ & $(0.80,0.15)$ & $(0.90,0.00)$ & $(0.70,0.05)$ \\
& $(0.80,0.10)$ & $(0.85,0.15)$ & $(0.95,0.00)$ & $(0.40,0.45)$ & $(0.50,0.25)$ & $(0.85,0.05)$ & $(0.95,0.00)$ & $(0.75,0.10)$ \\
\hline$c_{5}$ & $(0.80,0.10)$ & $(0.50,0.40)$ & $(0.80,0.05)$ & $(0.80,0.20)$ & $(0.60,0.30)$ & $(0.50,0.30)$ & $(0.60,0.25)$ & $(0.60,0.20)$ \\
& $(0.70,0.05)$ & $(0.45,0.35)$ & $(0.90,0.15)$ & $(0.85,0.15)$ & $(0.50,0.25)$ & $(0.45,0.35)$ & $(0.65,0.35)$ & $(0.50,0.15)$ \\
& $(0.90,0.15)$ & $(0.55,0.45)$ & $(0.70,0.10)$ & $(0.75,0.25)$ & $(0.70,0.35)$ & $(0.55,0.25)$ & $(0.55,0.30)$ & $(0.70,0.25)$ \\
\hline
\end{tabular}

The data in the Table above can be represented by a matrix given as, $\left[\begin{array}{lll}\mu^{1} & \nu^{1} & \pi^{1} \\ \mu^{2} & v^{2} & \pi^{2} \\ \mu^{3} & v^{3} & \pi^{3}\end{array}\right]$, where the first row represents an
IFMS data for the first committee, second row represents an IFMS data for the second committee, and the third row represents an IFMS data for the third committee, where $\pi^{\mathrm{i}}=$ $1-\mu^{i}-v^{i}$ for $i=1,2,3$. 
Applying the method in [6], the intuitionistic fuzzy multi-data

become intuitionistic fuzzy data as shown in the Table below.

Table 2. Candidates and Qualifications

\begin{tabular}{|c|c|c|c|c|c|c|c|c|}
\hline & honesty & team spirit & hard working & transparency & $\begin{array}{l}\text { academic } \\
\text { fitness }\end{array}$ & experience & accountability & probity \\
\hline$c_{1}$ & $(0.5,0.4)$ & $(0.8,0.2)$ & $(0.4,0.3)$ & $(0.4,0.5)$ & $(0.6,0.2)$ & $(0.7,0.1)$ & $(0.8,0.1)$ & $(0.7,0.2)$ \\
\hline$c_{2}$ & $(0.8,0.2)$ & $(0.6,0.3)$ & $(0.6,0.1)$ & $(0.3,0.5)$ & $(0.8,0.1)$ & $(0.8,0.1)$ & $(0.9,0.0)$ & $(0.8,0.1)$ \\
\hline$c_{3}$ & $(0.6,0.3)$ & $(0.7,0.3)$ & $(0.7,0.2)$ & $(0.2,0.6)$ & $(0.9,0.1)$ & $(0.8,0.2)$ & $(0.9,0.1)$ & $(0.7,0.2)$ \\
\hline$c_{4}$ & $(0.7,0.1)$ & $(0.8,0.1)$ & $(0.9,0.0)$ & $(0.5,0.4)$ & $(0.5,0.3)$ & $(0.8,0.1)$ & $(0.9,0.0)$ & $(0.7,0.1)$ \\
\hline$c_{5}$ & $(0.8,0.1)$ & $(0.5,0.4)$ & $(0.8,0.1)$ & $(0.8,0.2)$ & $(0.6,0.3)$ & $(0.5,0.3)$ & $(0.6,0.3)$ & $(0.6,0.2)$ \\
\hline
\end{tabular}

The Table below is assumed to be the organization requirements for appointment into the five positions or offices.

Table 3. Positions and Qualifications

\begin{tabular}{|c|l|l|l|l|l|l|l|l|}
\hline & honesty & team spirit & hard working & transparency & $\begin{array}{l}\text { academic } \\
\text { fitness }\end{array}$ & experience & accountability & probity \\
\hline$p_{1}$ & $(0.6,0.3)$ & $(0.5,0.4)$ & $(0.7,0.2)$ & $(0.6,0.3)$ & $(0.5,0.3)$ & $(0.5,0.4)$ & $(0.6,0.2)$ & $(0.7,0.3)$ \\
\hline$p_{2}$ & $(0.7,0.2)$ & $(0.8,0.1)$ & $(0.7,0.1)$ & $(0.6,0.3)$ & $(0.8,0.1)$ & $(0.8,0.0)$ & $(0.7,0.1)$ & $(0.9,0.0)$ \\
\hline$p_{3}$ & $(0.8,0.1)$ & $(0.7,0.2)$ & $(0.8,0.1)$ & $(0.7,0.1)$ & $(0.8,0.1)$ & $(0.8,0.1)$ & $(0.6,0.2)$ & $(0.8,0.2)$ \\
\hline$p_{4}$ & $(0.6,0.3)$ & $(0.5,0.3)$ & $(0.6,0.2)$ & $(0.4,0.4)$ & $(0.6,0.1)$ & $(0.5,0.4)$ & $(0.5,0.3)$ & $(0.6,0.3)$ \\
\hline$p_{5}$ & $(0.4,0.5)$ & $(0.5,0.2)$ & $(0.5,0.3)$ & $(0.6,0.4)$ & $(0.6,0.3)$ & $(0.5,0.3)$ & $(0.6,0.3)$ & $(0.6,0.1)$ \\
\hline
\end{tabular}

Using Def. 2.7, the distance between the positions and the candidates with respect to each of the qualifications is calculated and the Table below is obtained.

Table 4. Candidates and Positions

\begin{tabular}{|c|c|c|c|c|c|}
\hline & $p_{1}$ & $p_{2}$ & $p_{3}$ & $p_{4}$ & $p_{5}$ \\
\hline$c_{1}$ & 0.0438 & 0.0406 & 0.0516 & 0.0406 & 0.0359 \\
\hline$c_{2}$ & 0.0219 & 0.0297 & 0.0313 & 0.0484 & 0.0547 \\
\hline$c_{3}$ & 0.0469 & 0.0344 & 0.0375 & 0.0484 & 0.0578 \\
\hline$c_{4}$ & 0.0438 & 0.0344 & 0.0375 & 0.0531 & 0.0578 \\
\hline$c_{5}$ & 0.0250 & 0.0500 & 0.0320 & 0.0359 & 0.0313 \\
\hline
\end{tabular}

From the Table above, the following decision are made on shortest distance bases between the candidates $c_{i}$ and the positions $p_{i}$ for $i=1,2,3,4,5$. Candidate $c_{1}$ can assist $c_{5}$ in $p_{5}$. Candidate $c_{2}$ is fit for $p_{1}$. Candidates $c_{3}$ is fit for $p_{2}$ and $c_{4}$ can assist $c_{5}$ in $p_{3}$ and also fit for $p_{2}$. Candidate $c_{5}$ is fit for $\mathrm{p}_{5}$ an

\section{CONCLUSION}

Intuitionistic fuzzy multiset is a veritable tool in decision making. This method curbed the leeway for possible manipulations because of the intuitionistic fuzzy multi-nature of the exercise. If incorporated into appointment procedure, it will enhance high rate of efficiency and performance in organizations. Intuitionistic fuzzy multisets is recommended for application in pattern recognition, medical imaging etc.

\section{ACKNOWLEDGMENTS}

The authors express their sincere thanks to the anonymous reviewers for their valuable comments and suggestions.

\section{REFERENCES}

[1] Atanassov, K.T. 1983. Intuitionistic fuzzy sets, VII ITKR's Session, Sofia.

[2] Atanassov, K.T. 1999. Intuitionistic fuzzy sets: theory and application, Springer-Verlay.

[3] Das, S., Kar, M.B., Kar, S. 2013. Group multi-criteria decision making using intuitionistic multi-fuzzy sets, J. of Uncertainty Analysis and Applications, 1 (10) 1-16. 
[4] Deepa, C. 2014. Some implication results related to intuitionistic fuzzy multisets. Int. J. of Advance Research in Computer Science and Software Engineering, 5 (4) 361-365.

[5] Ejegwa, P.A. 2015. New operations on intuitionistic fuzzy multisets, J. of Mathematics and Informatics 3, 1723.

[6] Ejegwa, P.A. 2015. Mathematical techniques to transform intuitionistic fuzzy multisets to fuzzy sets, J. of Information and Computing Science 10 (2) 169-172.

[7] Ejegwa, P.A. 2015. Intuitionistic fuzzy sets approach in appointment of positions in an organization via maxmin-max rule, Global J. of Sci. Frontier Research: Math. \& Decision Sciences 15 (6) 1-5.

[8] Ejegwa, P.A. 2014. On difference and symmetric difference operations on intuitionistic fuzzy multisets, J. of Global Research in Mathematical Archives 2 (10) 1621.

[9] Ejegwa, P.A., Awolola, J.A. 2013. Some algebraic structures of intuitionistic fuzzy multisets, Int. J. of Science \& Technology 2 (5) 373-376.

[10] Ejegwa, P.A., Edibo, O.P. 2014. Some distance measures between intuitionistic fuzzy multisets, Int. J. of Scientific \& Technology Research 3 (4) 332-334.

[11] Ejegwa, P.A., Awolola, J.A. 2014. Intuitionistic fuzzy multisets in binomial distributions, Int. J. of Scientific and Technology Research 3 (4) 335-337.

[12] Ejegwa, P.A., Modom, E.S. 2015. Diagnosis of viral hepatitis using new distance measure of intuitionistic fuzzy sets, Intern. J. of Fuzzy Mathematical Archive 8 (1) $1-7$.
[13] Ibrahim, A.M., Ejegwa, P.A. 2013. Some modal operators on intuitionistic fuzzy multisets, Int. J. of Engineering and Scientific Research 4 (9) 1814-1822.

[14] Rajarajeswari, P., Uma, N. 2013. A study of normalized geometric and normalized Hamming distance measures in intuitionistic fuzzy multisets, Int. J. of Science and Research, 2 (11) 76-80.

[15] Rajarajeswari, P., Uma, N. 2014. Correlation measure for intuitionistic fuzzy multisets, Int. J. of Research in Engineering and Technology, 3 (1) 611-617

[16] Rajarajeswari, P., Uma, N. 2014. Normalized Hamming similarity measures for intuitionistic fuzzy multisets and its application in medical diagnosis, Int. J. of Mathematics Trends and Technology, 5 (3) 219-225.

[17] Rajarajeswari, P., Uma, N. 2014. The Zhang and Fu's similarity measures on intuitionistic fuzzy multisets, Int. $\mathbf{J}$ of Innovation Research in Science, Engineering and Technology, 3 (5) 12309-12317.

[18] Shinoj, T.K., Sunil, J.J. 2012. Intuitionistic fuzzy multisets and its application in medical diagnosis, Int. J. of Mathematical and Computational Sciences 6 34-38.

[19] Shinoj, T.K., Sunil, J.J. 2013. Intuitionistic fuzzy multisets, Int. J. of Engineering Science and Innovative Technology 2 (6) 1-24.

[20] Shinoj, T.K., Sunil, J.J. 2013. Accuracy in collaborative robotics: an intuitionistic fuzzy multiset approach, Global J. of Sc. Frontier Research Math. and Decision Sciences 13 (10) 21-28.

[21] Yager, R.R. 1986. On the theory of bags, Int. J. of General Systems 13, 23-37. 